\title{
Sobre a objetividade do belo entre Kant e Hölderlin
}

Zur Objektivität des Schönen zwischen Kant und Hölderlin

\author{
Joãosinho Beckenkamp
}

\section{RESUMO}

Um ponto alto da aproximação de arte e verdade é dado sem dúvida com a filosofia alemã clássica, quer dizer, naquele desenvolvimento excepcional das ideias entre Kant e Hegel. Para compreender melhor este estreitamento de arte, filosofia e verdade, cumpre antes determinar o ponto de partida próximo deste desenvolvimento. Desafiado pela tese kantiana da subjetividade do belo, já Schiller procurou resgatar a objetividade do belo, o que pôde então ser desenvolvido ulteriormente por Hölderlin, para o qual finalmente arte e filosofia estão irmanadas no esforço de tornar consciente a unidade de todo ser como verdadeiro, bom e belo.

Palavras-chave: Beleza; Subjetividade; Objetividade; Kant; Schiller; Hölderlin.

\section{ZUSAMMENFASSUNG}

Ein Höhepunkt der Annäherung von Kunst und Wahrheit wird zweifelsohne in der klassischen deutschen Philosophie erreicht, $d$. h., in der hervorragenden Entwicklung aller Bereiche des Denkens und Dichtens zwischen Kant und Hegel. Um diese Verschränkung von Kunst, Philosophie und Wahrheit besser zu verstehen ist zunächst angebracht, den unmittelbaren Ausgangspunkt dieser Entwicklung näher zu bestimmen. Von Kants These der Subjektivität des Schönen angeregt versuchte nämlich schon Schiller zu einem neuen Verständnis der Objektivität des Schönen zu kommen, was dann von Hölderlin aufgenommen und weitergeführt wurde, bei dem endlich Kunst und Philosophie gleichermassen zur Bewusstmachung der Wahrheit beitragen.

Stichwörter: Schönheit; Subjektivität; Objektivität; Kant; Schiller; Hölderlin.

Professor do Departamento de Filosofia da Universidade Federal de Minas Gerais, possui Mestrado em Filosofia pela Universidade Federal do Rio Grande do Sul (UFRGS, 1987), fez estudos em nível de doutorado na Universidade de Göttingen (GAU, 1988-1993) e possui Doutorado em Filosofia pela Universidade Estadual de Campinas (UNICAMP, 1999). Em 2003-2004 realizou estágio pósdoutoral junto ao Arquivo Hegel (Bochum, Alemanha). Tem experiência na área de História da Filosofia, com ênfase na filosofia alemã clássica, atuando principalmente nos seguintes temas: crítica, filosofia kantiana e pós-kantiana, além de filosofia do direito natural e crítica da economia política, com vários artigos, livros e traduções publicados. 
Uma passagem da carta de Hölderlin a Neuffer de outubro de 1794, pode servir de ponto de orientação para a exposição de uma primeira rodada de discussão, que prepara a reivindicação de conteúdo de verdade para a arte tanto nos primeiros românticos alemães (cujo programa é desenvolvido e tornado público essencialmente entre 1797 e 1801) quanto em Hölderlin, assim como reverberá ainda na síntese final proposta pela estética hegeliana. Em sua carta, Hölderlin expõe uma ideia com que acredita poder contribuir para os projetos editoriais de seus amigos Neuffer e Konz: "Talvez eu possa mandar um ensaio sobre as ideias estéticas; uma vez que ele pode valer como um comentário sobre o Fedro de Platão, sendo uma passagem deste certamente meu texto, ele talvez fosse útil para Konz. Basicamente, ele deve conter uma análise do belo e sublime, pela qual a de Kant é simplificada e, por outro lado, tornada mais diversificada, como em parte já fez Schiller em seu texto sobre dignidade e graça, o qual, entretanto, deixou de ousar um passo a mais além do limite kantiano, que na minha opinião ele deveria ter ousado." (StA 6, 137).

Para entender do que se trata no passo que Hölderlin acredita que Schiller deveria ter dado para lá da análise kantiana do conceito do belo, é preciso antes de tudo recuperar o mérito e os limites da análise estética de Kant. O período de formação de Kant é marcado, em termos de estética, por duas correntes divergentes, uma um pouco mais antiga, de cunho racionalista, que defende a objetividade do belo, apreendido no objeto como sua perfeição; e outra mais recente, de origem inglesa e empirista, que contesta a objetividade do belo, defendendo que o belo corresponde a um sentimento peculiar de um indivíduo ou sujeito. Com sua Crítica da faculdade do juízo, de 1790, Kant se opõe às duas correntes, inaugurando de fato uma nova corrente, a cujos desdobramentos podemos assistir até nossos dias. Contra os racionalistas, Kant lembra que no belo está envolvido sempre um sentimento de prazer e que nenhum sentimento se presta à objetividade lógica ou cognitiva pressuposta na compreensão do belo como objeto perfeito; por este lado, então, Kant defende que os juízos estéticos não têm a mesma natureza dos juízos lógicos ou teóricos, expressando antes uma apreciação subjetiva, e não um juízo sobre o que o objeto é nele mesmo. Mas, surpreendentemente, Kant defende também, desta vez contra os empiristas ou subjetivistas ingleses, que os juízos estéticos levantam legitimamente uma pretensão de valerem universalmente. Para tanto, introduz a noção de universalidade subjetiva, que define 0 que pode ser uma universalidade estética: “a universalidade estética que se atribui a um juízo é de tipo especial, porque o predicado da beleza não se conecta com o conceito do objeto, considerado em toda a sua esfera lógica, e ainda assim se estende sobre toda a esfera dos julgadores." (KU, B 24); quer dizer, dos sujeitos que julgam e que de certa maneira são desafiados a uma concordância universal. Com isto, Kant logra tornar plausível que os juízos estéticos possam pretender universalidade, mas apenas com base na possível concordância dos sujeitos, ou seja, subjetivamente.

Contra esta circunscrição do juízo estético à esfera subjetiva Schiller toma publicamente posição em seu ensaio Sobre graça e dignidade, de 1793. Mas a ideia para um conceito objetivo do belo se forma no curso de suas lições sobre 
estética na Universidade de Jena durante o semestre de inverno de 1792/3. Deste projeto, Schiller dá notícia ao amigo Christian Körner em carta de 21 de dezembro de 1792: "Tive bastante luz sobre a natureza do belo, de modo que acredito ganhá-lo para a minha teoria. Acredito ter encontrado o conceito objetivo do belo, que ipso facto se qualifica também para um princípio objetivo do gosto, e que foi posto em dúvida por Kant. Vou ordenar meus pensamentos a respeito e publicar na próxima Páscoa num diálogo Kálias ou sobre a beleza.” (SW 5, 1199-1200). O projeto não foi levado a cabo, entretanto, tendo estas considerações de Schiller sobre um princípio objetivo do gosto ficado inéditas na época. $\mathrm{O}$ que Schiller procura com seu conceito objetivo do belo fica mais claro nas cartas a Körner do que em Sobre graça e dignidade. Tendo estreado na década anterior como dramaturgo, ao que voltaria, aliás, depois de sua larga excursão pelo campo da filosofia estética (entre 1790 e 1795), Schiller está interessado num conceito de belo como exposição de ideias morais, o que em termos kantianos pode ser resumido a uma exposição da liberdade, visto que a moral em sentido kantiano apenas explicita as regras de realização da liberdade. Daí a hoje célebre definição de beleza na carta a Körner de 8 de fevereiro de 1793: "Beleza nada mais é do que liberdade na aparência.” (SW 5, 400). Para Kant, o mundo das aparências ou fenômenos é totalmente regido pelo princípio da necessidade causal, não sendo possível, por conseguinte, que a liberdade seja apresentada como fenômeno ou aparência. Ora, no teatro, assim como na relação comum dos homens livres entre si, pensa Schiller, temos a manifestação sensível da liberdade sob as mais diversas formas; neste quesito, portanto, Kant parece ter ido longe demais com seu rigorismo criticista, o que se expressaria então também em seu conceito subjetivista do belo, originalmente obtido a partir de considerações, não sobre ações livres dos homens, mas sobre manifestações da natureza que evocam no espectador um sentimento de prazer sui generis que torna expresso quando julga que algo é belo. Como dramaturgo, Schiller precisa mais do que isto; ele precisa de um conceito do belo que lhe permita pensar a apresentação de ações livres ou morais no palco, sem que o processo descambe para um subjetivismo completo. $O$ conceito do belo como manifestação sensível de decisões e ações livres cumpre esta função.

A exposição deste conceito objetivo do belo em Sobre graça e dignidade, a que Hölderlin se refere em sua carta (e a única, aliás, a que podia ter acesso na época), é um pouco mais reticente, mas tem o mesmo sentido. Nela, Schiller considera que "há duas maneiras pelas quais aparências podem tornar-se objetos da razão e expressar ideias" (SW 5, 441), a saber, pela representação da perfeição encontrada no próprio objeto ou como representação da beleza, na qual a razão colocaria ou apresentaria simbolicamente nas aparências sua ideia: "Nem sempre é necessário que a razão retire estas ideias das aparências, ela também as pode introduzir nelas." (SW 5, 441). Sobretudo na consideração da graça e beleza de figuras humanas, esta maneira de conceber a apresentação sensível de uma ideia parece ser necessária, pois afinal "a beleza arquitetônica do homem é a expressão sensível de um conceito da razão" (SW 5, 443) e "na graça, como em geral na beleza, a razão vê satisfeita na sensibilidade a sua exigência, e surpreendentemente se depara com uma de 
suas ideias na aparência.” (SW 5, 482). Pelo contexto das cartas a Körner, está claro que Schiller pensa aqui na ideia de liberdade; mas, em vista da exposição dramatúrgica, o dito se aplica também a ideias morais derivadas, como generosidade e magnanimidade, por exemplo, ou ainda perseverança e fidelidade.

Apesar de forçar assim os limites da crítica kantiana no concernente à apresentação sensível de uma ideia da razão, Schiller não abandona o terreno da filosofia moral kantiana, na qual se encontra uma contraposição quase que absoluta entre razão e sensibilidade, liberdade e natureza, demandas da moral e demandas das paixões. Para expressar sua insatisfação com o rigorismo moral de Kant, Schiller concebe timidamente uma relação mais harmoniosa entre razão e sensibilidade, em que o jogo livre entre o imperativo moral e a resposta da natureza ou das paixões se manifesta como beleza. Com isto, introduz uma terceira possibilidade de relacionar razão e sensibilidade, ao lado das duas previstas pela moral kantiana, ou seja, o domínio monárquico da razão sobre as paixões (opção estoica) e a anarquia das paixões insubmissas à razão: "se nem a razão dominando a sensibilidade nem a sensibilidade dominando a razão são compatíveis com a beleza da expressão, então aquele estado do ânimo em que razão $e$ sensibilidade, dever e inclinação, concordam, será a condição sob a qual se segue a beleza do jogo.” (SW 5, 463). O passo que Schiller dá no sentido de reivindicar objetividade para a beleza tem como pano de fundo, portanto, a moral kantiana, a cujo serviço estará sua estética e, pouco mais tarde, também sua dramaturgia (como encenação exemplar da virtude diante das vicissitudes da vida). Aliás, promover a concordância da razão e da sensibilidade é o propósito fundamental da educação estética dos homens, objeto de sua obra seguinte.

Ora, no quadro da filosofia moral kantiana, a que se atêm Schiller e em seguida também Fichte, a plena concordância de razão e sensibilidade ou de espírito e natureza só se daria ao cabo de um progresso ou de um processo de aproximação infinitos, o que equivale a dizer que, para seres finitos como os homens, a harmonização ou reconciliação da razão ou do espírito com a sensibilidade ou a natureza é um ideal inatingível, dissipando-se na consciência de um simples dever ser, sem jamais adquirir o status ontológico do ser. $\mathrm{O}$ passo que Hölderlin ousa dar além de Kant e de Schiller, e com o qual abre um novo capítulo da história da filosofia alemã, consiste em romper num ponto específico com aquele quadro, localizando numa experiência dada a efetividade (e não mera possibilidade) da concordância ou unidade dos contrapostos.

Este passo decisivo é anunciado na carta a Neuffer de 1794 mediante uma referência vaga a uma passagem do Fedro de Platão. Mas, analisando de perto o diálogo de Platão e mantendo no horizonte o que Hölderlin fará em seguida, não é difícil identificar esta passagem; trata-se de Fedro 250b, onde Platão defende que a ideia de beleza se dintingue das demais ideias, como as de sabedoria e de justica, que jamais podem aparecer nas cópias sensíveis, mantendose sempre apenas como ideal a ser perseguido pelos homens em sua jornada pelo mundo sensível. Platão defende na mencionada passagem que a ideia de beleza se distingue das demais ideias como a única que é visível no que 
aparece. Assim, se as demais ideias só podem ser recuperadas pela anamnese ou rememoração, a ideia de beleza também se torna visível nas manifestações da natureza. Apropriando-se desta ideia platônica de uma beleza presente na natureza, Hölderlin consegue ir bem além de seus mentores iniciais Kant, Schiller e Fichte. Pois também Schiller, ao seguir Kant no concernente à necessária separação de sujeito e objeto em matéria de moral (filosofia prática), apenas insistindo também na necessidade da harmonização das duas esferas (razão e sensibilidade ou liberdade moral e natureza), dá prosseguimento à primeira parte da concepção platônica das ideias, dentro da qual a ideia originária não pode ser recuperada neste mundo ou na experiência dos homens; e, ao vacilar em relação à objetividade da beleza, Schiller deixa de dar um passo que Hölderlin pretende dar com apoio em Platão, apropriando-se da sutil segunda parte da concepção platônica das ideias desenvolvida no Fedro.

Na filosofia prática ou moral, a exigência da harmonização final da razão e da sensibilidade passa a ser respondida explicitamente a partir de Fichte pela concepção de uma aproximação infinita à identidade do sujeito e do objeto ou do eu e do não-eu, como Fichte se expressa em geral. Tendo assistido às lições de Fichte no início de 1795, Hölderlin retoma este desenvolvimento em meados de 1795 no prefácio da penúltima versão de seu Hipérion: "Mas nem nosso saber nem nosso agir chegam em qualquer período de nossa existência lá onde cessa todo antagonismo, lá onde tudo é um; a linha determinada só se une com a indeterminada em aproximação infinita." (StA 3, 236). Em vez de se contentar com a idealização da própria existência que decorre desta intransponível separação tanto na teoria quanto na prática, entretanto, Hölderlin propõe um aprofundamento da experiência estética, apropriando-se da concepção platônica da beleza como ideia que se manifesta na natureza: "Nós nem sequer teríamos um pressentimento daquela paz infinita, daquele ser, no sentido único da palavra, não aspiraríamos a unir conosco a natureza, não pensaríamos nem agiríamos, em geral não existiria nada (para nós), se ainda assim aquela união infinita, aquele ser, no sentido único da palavra, não fosse dado. Ele é dado - como beleza; para falar como Hipérion, aguarda-nos um novo reino, em que a beleza é rainha." (StA 3, 236-7).

Somente no senso estético da beleza é dada a unidade de todo ser ou, como Hölderlin havia dito numa passagem do fragmento Juízo e ser, cuja redação é geralmente datada de início de 1795, somente em intuição intelectual se pode ter ser pura e simplesmente: "Onde sujeito e objeto estão unidos pura e simplesmente, e não apenas em parte, portanto unidos de tal maneira que não se pode proceder a nenhuma partição sem lesar a essência daquilo que é para ser separado, ali e somente ali se pode falar de um ser puro e simples, como é o caso na intuição intelectual.” (StA 4, 216). Registrando naquele momento suas impressões da leitura de Fichte, Hölderlin vê no sentido da beleza, a ser promovido naturalmente pela arte, o único ponto de acesso a uma unidade que se perde com a reflexão na esfera do eu ou da consciência: como a consciência se constitui tão somente com a cisão de sujeito e objeto, movendo-se a reflexão sempre no âmbito desta cisão originária, mesmo lá onde chega à 
unidade parcial de um juízo sintético, aquela unidade originária estaria fora do alcance dos esforços humanos se não fosse dada num momento privilegiado da experiência, neste contexto caracterizado, em polêmica com as cláusulas impeditivas do criticismo kantiano, como intuição intelectual, a ser entendida como apreensão estética da beleza que é a unidade de todo ser.

A defesa do primado da experiência estética se encontra formulada de maneira tão incisiva no fragmento conhecido como "O mais antigo programa de sistema do idealismo alemão”, que houve quem reivindicasse sua autoria para Hölderlin, apesar de ter sido legado numa cópia com a letra de Hegel. Datado de fins de 1796 ou início de 1797, época em que Hölderlin, aliás, está ocupado com a versão definitiva de seu Hipérion, o fragmento começa com o projeto de transformação da metafísica em ética (naturalmente à maneira de Espinosa), mas acaba arrematando sua ideia de sistema com uma atividade estética, na qual se encontrariam poetas e filósofos: "Por fim, a ideia que reúne a todas, a ideia da beleza, tomando-se a palavra em sentido superior, platônico. Estou agora convencido de que o supremo ato da razão, aquele em que ela abarca todas as ideias, é um ato estético, e que verdade e bondade são irmanadas somente na beleza. O filósofo tem de possuir tanta força estética quanto o poeta.” (StA 4, 298). Esta aproximação do filósofo e do poeta ou da ciência e da arte constitui uma novidade, que será encontrada também na estética do primeiro romantismo alemão. Apesar de ter sido levada às suas últimas consequências apenas por Hölderlin, que finalmente ensaiará sua junção na poética do período maduro, a ideia de que no fundo a filosofia e a arte estão irmanadas no propósito comum de promover a experiência da verdade, da bondade e da beleza vinha sendo defendida e executada por Fichte desde meados de 1794, particularmente em suas Lições sobre a destinação do erudito, de que Hölderlin dá notícia a Hegel numa carta de janeiro de 1795. Lugar-comum da filosofia da arte, também Kant e Schiller consideram essencial que o artista possua espírito ou, como definido na Crítica da faculdade do juízo, "princípio vivificante no ânimo” (KU, B 192); sem esta capacidade de vivificar sua matéria, o pretenso artista só deixa uma forma ou letra morta. Ora, Fichte inaugura na época uma nova maneira de fazer filosofia, tanto em suas aulas quanto em seus escritos, uma filosofia que se propõe ao mesmo tempo ser expressão de seu espírito e promover o despertar e o evoluir do espírito nos seus leitores e ouvintes. Com base nesta nova ou renovada concepção da filosofia como atividade essencialmente espiritual, Fichte passa a polemizar com os filósofos convencionais classificando-os de filósofos ocupados apenas com a letra (Buchstabenphilosophen), enquanto ele se dispõe a desenvolver uma filosofia que promove o espírito. Esta polêmica reverbera no mencionado fragmento seminal do idealismo alemão, acrescida de uma ênfase particular no momento estético: "Os homens sem senso estético são nossos filósofos da letra. A filosofia do espírito é uma filosofia estética. Não se pode ser espirituoso em nada, até mesmo sobre história não se pode raciocinar de forma espirituosa - sem senso estético. Aqui deve tornar-se patente o que propriamente falta aos 
homens que não entendem ideias - e admitem bastante ingenuamente que tudo lhes é obscuro assim que vai além de tabelas e registros.” (StA 4, 298).

As reflexões de Fichte sobre espírito e letra na filosofia não foram publicadas naquele período, mas Hölderlin teve larga ocasião de tomar conhecimento delas em sua estadia em Jena nos primeiros meses de 1795, quando assistiu mesmo às aulas de Fichte. Esta circunstância é importante porque as considerações de Fichte nesta ocasião sobre a função da arte e da filosofia na tomada de consciência do que nos aparece obscuramente no sentimento terão diversas repercussões nas reflexões estéticas de Hölderlin nos anos seguintes. Assim, nas lições intermediárias sobre a destinação do erudito, aquelas dedicadas ao papel do filósofo, Fichte dava grande importância à capacidade de elevar sentimentos à consciência, ou seja, de tornar consciente aquilo que se manifesta ainda inconscientemente no sentimento: "Encontra-se no sentimento o que a imaginação forma e fornece à consciência. $O$ sentimento é a matéria de tudo o que é representado, e o espírito em geral ou a imaginação produtiva pode ser descrito de acordo com isto como a faculdade de elevar sentimentos à consciência.” (GA II/3, 317). Sem ainda nos preocuparmos com o sentido que isto pode ter para Fichte, cabe registrar no coração mesmo de suas lições sobre o papel da filosofia a presença de temas muito caros a Hölderlin, como este da relação entre sentimento (que para o poeta é signo da natureza) e verdade, que um leitor superficial de Fichte deve achar muito surpreendente: “ $O$ sentimento indica o caminho onde a verdade poderia estar; mas também só indica, não fornece a verdade. Todos vocês que alguma vez me ouviram sabem que eu construo tudo no espírito humano sobre o sentimento; mas vocês me teriam entendido muito mal se acreditassem que em minha opinião nos deveríamos dar por satisfeito com o sentimento em relação a qualquer objeto. O sentimento precisa ser aclarado e desenvolvido, ele tem de ser separado e determinado pelo juízo. Elevar seu sentimento à clara consciência é espírito: apelar para seu mero sentimento como uma prova é falta de espírito, a rica e inesgotável fonte de todo devaneio.” (GA II/3, 337).

A concepção de uma atividade espiritual destinada a elevar à consciência o impulso originário de autoatividade que se expressa como sentimento (este é o sentido das reflexões de Fichte) ecoa longamente nas reflexões teóricas de Hölderlin, que lhe confere, entretanto, outro sentido. É o que se pode ver, por exemplo, numa carta ao irmão de junho de 1799, na qual, contra uma opinião largamente estabelecida, que contrapõe arte e natureza como polos mutuamente excludentes, Hölderlin diz que pretende defender o paradoxo de "que o impulso artístico e formativo, com todas as suas modificações e variedades, é propriamente um serviço que os homens prestam à natureza.” (StA 6, 329). Este serviço à natureza é a tarefa tanto da arte e da religião quanto da filosofia: "estamos de acordo em que todas as correntes errantes da atividade humana correm para o oceano da natureza, tal qual dele partem. E justamente mostrar este caminho, que os homens trilham em grande parte às cegas, seguidamente a contragosto e demasiadas vezes 
de maneira vil e desprezível, mostrar-lhes este caminho, a fim de que o trilhem com olhos abertos, com alegria e nobreza, esta é a tarefa da filosofia, da bela arte, da religião, as quais procedem também daquele impulso. A filosofia traz aquele impulso à consciência, mostra-lhe seu objeto infinito no ideal, fortalecendo-o e purificando-o através deste. A bela arte apresenta àquele impulso seu objeto infinito numa imagem viva, na representação de um mundo mais elevado; e a religião lhe ensina a pressentir e a crer aquele mundo mais elevado onde o procura e quer criar, quer dizer, na natureza, no seu próprio mundo e no que o rodeia, como uma disposição oculta, como um espírito que quer ser desenvolvido.” (StA 6, 329). À filosofia e à arte, como atividades espirituais por excelência em Fichte, Hölderlin acrescenta, portanto, a religião, num sentido que o contexto deixa claro: capacidade de pressentir em e com a natureza o elevado ideal da unidade originária de todo ser.

Tendo em mente estes desdobramentos, percebese o que há de continuidade e descontinuidade em relação a Fichte na mencionada passagem do fragmento "O mais antigo programa de sistema do idealismo alemão": "A poesia adquire com isto uma dignidade superior, ela volta a ser no final o que era no começo mestra da humanidade; pois já não há filosofia nem história, apenas a arte poética sobreviverá a todas as demais ciências e artes.” (StA 4, 298). O fragmento repercute aqui, naturalmente, um elemento rousseauniano, reforçado em 1789 no poema Os artistas de Schiller, que assim afirmava neste período o primado da arte, atribuindo-lhe uma última função, a de consumar a teleologia da história, fazendo a coleta final dos resultados parciais alcançados pela ciência, com o que a arte abre e fecha o processo histórico do espírito: “Com vocês [artistas], primeira planta da primavera, / Começou a natureza formadora de almas, / Com vocês, jovial coroa da colheita, / Encerra a natureza consumada." (v. 393-6).

Conhece-se bem a dificuldade que a busca de uma origem da história humana por parte de Rousseau (Discurso sobre as artes e as ciências, 1750; Discurso sobre a origem e os fundamentos da desigualdade entre os homens, 1755) legou aos alemães, deflagrando de certa maneira aquele processo especulativo que de Hamann e Herder a Kant e Hegel fundou algo assim como uma filosofia da história. Neste desenvolvimento, a questão da origem da história, quer dizer, do processo civilizatório e, portanto, do homem como o entendemos hoje, é colocada em lugares e momentos diferentes. Não podendo explicar esta origem a partir da animalidade do homem, já que os animais em geral não fazem história, Rousseau havia projetado a origem num tempo fictício entre o homem como animal e o homem em sociedade, um tempo feliz em que o homem recebe agradecido da natureza os dons que lhe permitem subsistir, o tempo de Saturno, tempo de coexistência pacífica dos homens. Kant, que basicamente segue Rousseau em sua filosofia da história, procurando tornar consistente as ideias aparentemente paradoxais do pensador genebrino, faz suas conjecturas sobre a origem da história humana (1786) interpretando a narrativa bíblica da queda do primeiro casal e da expulsão do paraíso. Por natureza, quer 
dizer, guiado pelo instinto ou pelo impulso natural, o homem não é bom nem mau; ele se torna um ou outro somente com o uso de sua razão, e aí ele começa mal, usando sua razão para promover o próprio apetite. A história do homem é então a história dos conflitos que o abuso da reflexão e da razão só faz aumentar, restando apenas a esperança de que a história o leve finalmente ao uso adequado de sua razão, ou seja, à superação da própria história das mazelas humanas.

Este é o horizonte histórico-filosófico em que Hölderlin ensaia uma recuperação da origem a partir de uma leitura da Grécia arcaica, em que poetas como Homero e Hesíodo puderam dar a seu povo os deuses de que precisavam para representar sua própria natureza divina. Seguindo Winckelmann, Hölderlin considera no Hipérion que os gregos só puderam atingir aquele pico cultural jamais ultrapassado porque viviam relativamente isolados e afastados de outros povos, com civilizações mais avançadas. Diferente de Rousseau, entretanto, que prefere a virtude estoica dos espartanos, Hölderlin busca a origem dos seus interesses junto aos atenienses: "deixai que o homem saiba apenas tardiamente que há homens, sim, que há qualquer coisa fora dele, pois somente assim ele se torna homem. Mas o homem é um deus desde que é homem. E, se é um deus, ele é belo. [...] Assim o ateniense era um homem, assim ele tinha de se torná-lo. Ele saiu belo das mãos da natureza, belo em corpo e alma, como se costuma dizer." (StA 3, 79). Tendo assim se desenvolvido natural e livremente, o povo ateniense apresenta em si mesmo o ideal de beleza, ao mesmo tempo que reúne de maneira excelente os requisitos para representar esta sua humana e divina beleza. E a primeira forma de expressão desta sua natureza o homem grego encontra na arte: "O primeiro filho da humana e divina beleza é a arte. Nela se rejuvenesce e se restabelece a si mesmo o divino homem. Ele quer sentir a si mesmo, por isto ele contrapõe sua beleza a si mesmo. Assim o homem se deu seus deuses. Pois no início o homem e seus deuses eram um, quando, desconhecida de si mesma, existia a eterna beleza.” (StA 3, 79).

Mas já os gregos foram além desta unidade do homem com a natureza e seus deuses, passando a refletir sobre a eterna beleza que até então (início do século quinto antes de nossa era, digamos) existia desconhecida de si mesma, ou seja, sem que fosse refletida pelas artes, condição para que um povo tome consciência de sua própria natureza divina. O Hipérion atribui este processo de reflexão sobre si mesmo à filosofia, mas ele pode ser visto em todos os momentos da cultura ateniense no século de Péricles e Sócrates. O que este processo cultural tornou patente é que a totalidade do ser que se mostra como beleza não tem a natureza de um monobloco indiferenciado em si mesmo, mas constitui uma unidade que se diferencia em si mesma, manifestando-se tanto na harmonia que expressa a unidade quanto nas dissonâncias que expressam as diferenças. Assim, já no primeiro volume do Hipérion, concluído em 1796, Hölderlin chega a pensar a "essência da beleza” pelo princípio da diferenciação, lembrando as palavras atribuídas a Heráclito:

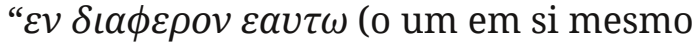
diferente)" (StA 3, 81). 
Esta compreensão da beleza como unidade que se diferencia em si mesma marca em seguida toda a lírica madura e tardia de Hölderlin, preservando-se a fidelidade àquele ser uno, verdadeiro, bom e belo, subjacente a todos os desenvolvimentos históricos e culturais, mesmo quando os acontecimentos são tão avassaladores, que de imediato deixam os homens sem palavra. Mas isto já é outra história.

\section{REFERÊNCIAS}

FICHTE, Johann Gottlieb. Gesamtausgabe der Bayerischen Akademie der Wissenschaften. Stuttgart/Bad Cannstatt: Frommann-Holzboog, 1962ss. [Citação: GA vol., pág.]

HÖLDERLIN, Friedrich. Sämtliche Werke. Stuttgart: Kohlhammer Verlag, 1943-1961. [Citação: StA vol., pág.]

KANT, Immanuel. Kritik der Urteilskraft. Berlin: Walter de Gruyter, 1908. [Citação: KU]

SCHILLER, Friedrich. Sämtliche Werke. München: dtv, 2004. [Citação: SW vol., pág.] 